\title{
Effects of the Acrylic Polyol Structure and the Selectivity of the Employed Catalyst on the Performance of Two-Component Aqueous Polyurethane Coatings
}

\author{
Suzana Cakic ${ }^{1}$, Caslav Lacnjevac ${ }^{2 *}$, Jakov Stamenkovic ${ }^{1}$, Nikola Ristic ${ }^{2}$, Ljiljana Takic ${ }^{1}$, \\ Miroljub Barac $^{2}$ and Miladin Gligoric ${ }^{3}$ \\ ${ }^{1}$ Faculty of Technology, 16000 Leskovac, Bul. oslobodjenja 124, Serbia Suzana Cakic, e-mail: \\ suzana_cakic@yahoo.com, Ljiljana Takic, e-mail: 1jilja_t@yahoo.com Jakov Stamenkovic, e-mail: \\ jakov_stamenkovic@yahoo.com, ${ }^{2}$ Faculty of Agriculture, 11080 Belgrade-Zemun, St. Nemanjina 6, \\ Serbia, Caslav Lacnjevac, e-mail: ukilaki@eunet.yu or lcaja@agrifaculty.bg.ac.yu, Miroljub Barac, e- \\ mail: baracm@agrifaculty.bg.ac.yu, Nikola Ristic, e-mail nristic@agrifaculty.bg.ac.yu, ${ }^{3}$ Faculty of \\ Technology, Zvornik, BIH, Miladin Gligoric, e-mail: lcaja@agrifaculty.bg.ac.yu＊To whom \\ correspondence should be addressed. E-mail: ukilaki@eunet.yu or lcaja@agrifaculty.bg.ac.yu
}

Received: 6 February 2007 / Accepted: 8 March 2007 / Published: 13 March 2007

\begin{abstract}
Two kinds of aqueous acrylic polyols (single step and multi step synthesis type) have been investigated for their performance in the two-component aqueous polyurethane application, by using more selective catalysts. The aliphatic polyfunctional isocyanates based on hexamethylen diisocyanates have been employed as suitable hardeners. The complex of zirconium, commercially known as K-KAT ${ }^{\circledR} \mathrm{XC}-6212$, and manganese (III) complexes with mixed ligands based on the derivative of maleic acid have been used as catalysts in this study. Both of the aqueous polyols give good results, in terms of application and hardness, when elevated temperatures and more selective catalysts are applied. A more selective catalyst promotes the reaction between the isocyanate and polyol component. This increases the percentage of urethane bonds and the degree of hardness in the films formed from the two components of aqueous polyurethane lacquers. The polyol based on the single step synthesis route is favourable concerning potlife and hardness. The obtained results show that the performance of the two-component aqueous polyurethane coatings depends on the polymer structure of the polyols as well as on the selectivity of the employed catalyst.
\end{abstract}

Keywords: aqueous polyurethanes, catalyst's selectivity, König hardness and induction time. 


\section{Introduction}

Conventional two-component polyurethane systems (2C-PU) are successfully used in various applications. Typical examples are OEM topcoats and clear coats, automotive repair coatings (fillers, clearcoats and topcoats), industrial paints, furniture lacquers, plastic coatings etc. The unique crosslinking chemistry, based on the addition reaction of $\mathrm{OH}$ functional binders with polyisocyanate hardeners, results in high-molecular weight of polyurethanes with excellent outdoor durability, outstanding chemical resistance and very good mechanical properties. The urethane linkage in the polymer backbone provides high resistance against chemicals (solvents as well as acids and bases) and the high density of hydrogen bonding results in the formation of a stable physical network, which contributes to the good mechanical properties of the coating. Among various options for very low emission coatings, the aqueous binders generally have a big potential for improvements in VOC (volatile organic compound(s)). In addition to the usual problems, which generally result from the use of water as solvent, the 2C-PU crosslinking suffers from a special problem, the undesired secondary reaction of the polyisocyanate hardener with water [1-4].

The basic principle in the two-component polyurethane coatings is high reactivity of the isocyanate group of the polyfunctional isocyanates that reacts easily with the hydroxyl polymer groups, thus forming stable polyurethanes and creating the transversal binding structure [3-6]. If the system contains water, then the reaction of the isocyanate group with water leads to the occurrence of the primary amine and further to the formation of polyurea with the simultaneous evolution of carbon dioxide. The reactions with water are not desirable because the isocyanate groups that react with water are not available for the crosslinking with polyol, and the created carbon dioxide can be captured in the form of bubbles in the dry film.
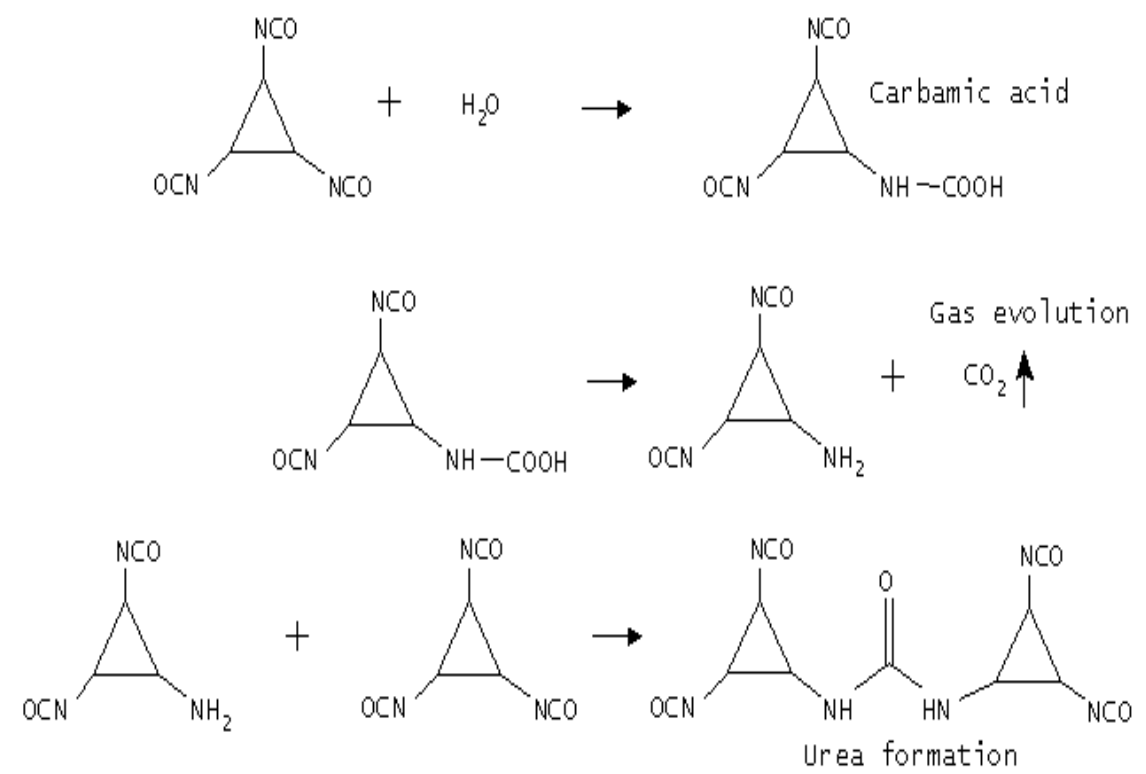

Figure 1. Isocyanate reactions with $\mathrm{H}_{2} \mathrm{O}$ 
The main aspect in the development of the polyurethanes is, in the first place, to find methods for preventing the undesired secondary reactions with water and for achieving the best crosslinking. This reaction is reduced to a minimum by use of the non-tin catalysts.

In the researches of Werner Blank [7,8] the selectivity of various compounds compared to model compounds has been examined. Butyl isocyanate and 2-ethyl-1-hexanol have been selected as model compounds because of their similarities with the aliphatic polyisocyanates and hydroxyl resins as well as on account of the simplicity of their FTIR spectra. The compounds examined as catalysts in the present study are as follows: the compounds of octonates of $\mathrm{Zn}$, Co and $\mathrm{Mn}$, the acetylacetonates of $\mathrm{Co}, \mathrm{Zn}, \mathrm{Ni}, \mathrm{Al}$ and Mn (Merck-Schuchardt), the catalyst of zirconium designated K-KAT ${ }^{\circledR} \mathrm{XC}-6212$ [9] (King industries, Norwalk-USA), as well as the complexes of manganese with various ligands.

The relation of the surface of IR urethane strips $\left(\mathrm{P}_{\text {urethane }}\right)$ to urea $\left(\mathrm{P}_{\text {urea }}\right)$ has been used as the measure of the relative selectivity (S).

$$
\mathrm{S}=\mathrm{P}_{\text {urethane }} / \mathrm{P}_{\text {urea }}
$$

The complex of Mn (III)-diacetylacetonatomaleate with various ligands based on the acetylacetonate and maleic acid [10,11] shows high selectivity for the isocyanate-hydroxyl reaction.

The effect of the catalysts of different selectivity has been observed indirectly by measuring the mechanical-optical parameters of the formed films [12].

An appropriate modification in the hardener's component (hydrophilic polyisocyanates) has improved the dispersity of the hardener and the ease of mixing, but the extensive hydrophilic modification may cause drawbacks in hardness and chemical resistance. Sophisticated mixing equipment is another tool to overcome some of the problems, but the use of this kind of equipment has not really been accepted in the paint industry [13-14].

The optimization of the polyol component is another measure that can contribute much to the performance of the 2C-PU system. The polyol in the aqueous 2C-PU systems supports the dispersity and quick incorporation of the polyisocyanate hardener.

The objective of this work has been to study the effects of the synthesis route of the aqueous acrylic polyols as well as of the selectivity of the employed catalyst on the applications in the two-component aqueous polyurethane systems.

\subsection{Acrylic Polyol Synthesis}

The aqueous acrylic polyols used for crosslinking of the systems are of low to medium molecular weight polymers that are stabilized in the aqueous phase, mainly electrostatically. Thus, the amine salts of pendant carboxyl groups are formed. In the aqueous binders, the creation of the rheological behaviour is one of the clues for successful applications. Rheology can be affected by various parameters, one of the most important being suitably created polymer segmentation. It has been proved that the polymer structures with separated hydrophilic and hydrophobic segments exhibit better rheology than others in the cases where these functions are evenly distributed along the polymer backbone. Actually, different synthesis routes are used to build the polymers of the segmented hydrophilic-hydrophobic structure. 
Single step synthesis

The single step synthesis route is based on a special solution polymerization technique, which additionally utilizes the reaction between the oxirane and acid groups to produce the aqueous binders suitable for a $1 C$ application. After charging an oxirane-functional component, a monomer mixture containing carboxyl and hydroxyl functional monomers is being fed into the reactor at a constant feed rate and polymerized continuously. During the early polymerization stages the carboxyl groups of the polymer are consumed by the oxirane component and ester linkages are formed.<smiles></smiles>

Figure 2. Reaction of oxirane and acid

In this way the non-ionic, hydrophobic polymer segments are created during the first stages of the polymerization, whereas the ionic, hydrophilic polymer structures are formed in the final reaction period, when all the available oxirane functionality has been consumed. Finally, the polymer is neutralized and emulsified by the addition of water.

Multi step synthesis

The synthesis route is subdivided into several steps. Carboxyl-functional (hydrophilic) and hydroxyl-functional (hydrophobic) acrylic intermediates are made separately by applying the solution polymerization techniques. Upon partial coesterification of the two intermediates, a water-soluble polymer is formed and it is consecutively emulsified by neutralizing the mixture with amine (dimethyl ethanol amine, DMEA) and by the addition of water. The polymers of this type have been successfully used in thermosetting applications for years. The surface properties, e.g. leveling of the existing 1C type of polymers, are rather poor with the low temperature $2 \mathrm{C}$ systems. Therefore, the flow properties have had to be improved, which has been achieved mainly by lowering the molecular weight.

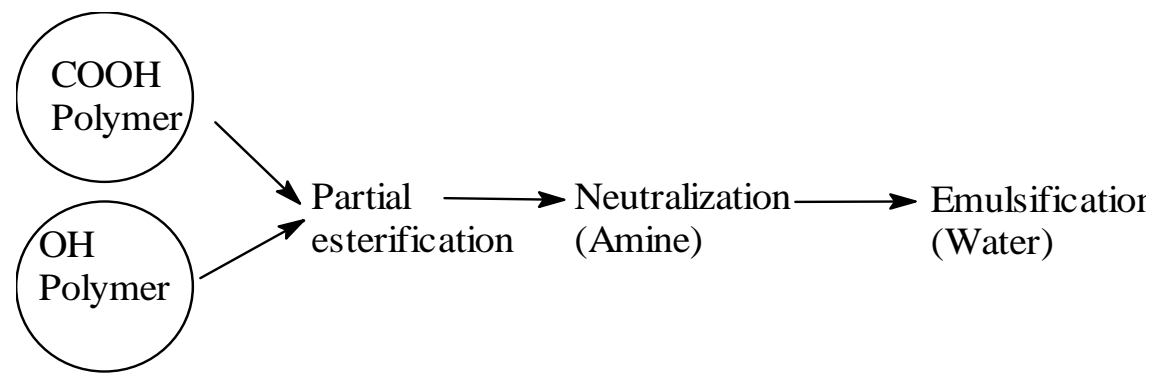

Figure 3. Multistep synthesis scheme 


\section{Experimental}

The polyol dispersions described in Table 1 have been crosslinked with the commercially available polyisocyanate hardeners (Bayer AG Germany). A mixture of the hydrophobic isocyanate of the hexamethylene diisocyanate trimer type (Desmodur 3600) containing 23\% NCO and a hydrophilic modified type (Bayhydur VP LS 2319) with 18.2\% NCO (ratio 4:6) has been used in the proportion NCO: $\mathrm{OH}$ of 1.5 . The catalyst concentrated $2 \%$ relating to the coating hardness has been added after the certain induction time.

Table 1. Characterization of the acrylic polyol dispersions [15].

\begin{tabular}{lll}
\hline Characteristic & Polyol*1 & Polyol*2 \\
\hline Synthesis route & Single step & Multi step \\
\hline $\begin{array}{l}\text { Solids [\%]; } \\
\text { DIN ISO 3251 }\end{array}$ & 42 & 43 \\
\hline $\begin{array}{l}\text { Acid value [mg/g]; } \\
\text { DIN ISO 3682 }\end{array}$ & 30 & 36 \\
\hline $\begin{array}{l}\text { Hydroxyl value [mg/g]; } \\
\text { DIN 53240 }\end{array}$ & 130 & 110 \\
\hline $\begin{array}{l}\text { Dynamic viscosity } \\
\text { DIN EN ISO 3219 }\end{array}$ & 2000 & 1500 \\
\hline Cosolvents [\%] & 4 & 12 \\
\hline VOC [ g/l ] & 90 & 239 \\
\hline \begin{tabular}{l} 
Particle size [nm] \\
\hline
\end{tabular} & $120 \mathrm{~nm}$ & $180 \mathrm{~nm}$ \\
\hline
\end{tabular}

Table 2 shows the composition of the employed components.

Table 2. Characteristics of the two-component aqueous polyurethane paints

\begin{tabular}{lcc}
\hline & PUR 1 & PUR 2 \\
\hline Component A , mass \% & & - \\
\hline Polyol *1 & 65.21 & 65.21 \\
\hline Polyol *2 & 8.69 & 8.69 \\
\hline Water & & \\
\hline Component B, mass \% & 13.04 & 13.04 \\
\hline Bayhydur VP LS 2319 & 8.69 & 8.69 \\
\hline Dezmodur N 3600 & 4.34 & 4.34 \\
\hline Methoxypropyl acetate & 0.98 & 0.99 \\
\hline Catalyst & & \\
$(2 \%$ relating to coating hardness) & 49.11 & 49.76 \\
\hline Paint solids (\%) & 100.95 & 100.08 \\
\hline Total mass of components & & \\
\hline
\end{tabular}


The defining of the König hardness of the varnish paint films has been carried out by using the method (JUS H. C. 8.055) that requires the determination of hardness in an indirect way by measuring the time period during which the oscillation amplitude of the pendulum leaned against the polymer dry film becomes smaller.

Apart from the hardness measuring, the change of gloss of the dried films has also been examined using the method according to Dr Lange (ISO 2813).

\section{Results and Discussion}

\subsection{Crosslinking}

Crosslinking depends very much on a drying temperature. Elevated temperatures are preferably used in some industrial applications, but in a lot of cases (with heavy and bulky substrates) the reaction must take place at ambient temperature only. A serious and, in terms of practice, relevant evaluation must consider both cases. Therefore, the following conditions have been tested: one and seven days' drying at ambient temperature $\left(21^{\circ} \mathrm{C}\right)$, and the forced drying at $60^{\circ} \mathrm{C}$ for $30 \mathrm{~min}$ followed by one and seven days' drying at $21^{\circ} \mathrm{C}$.

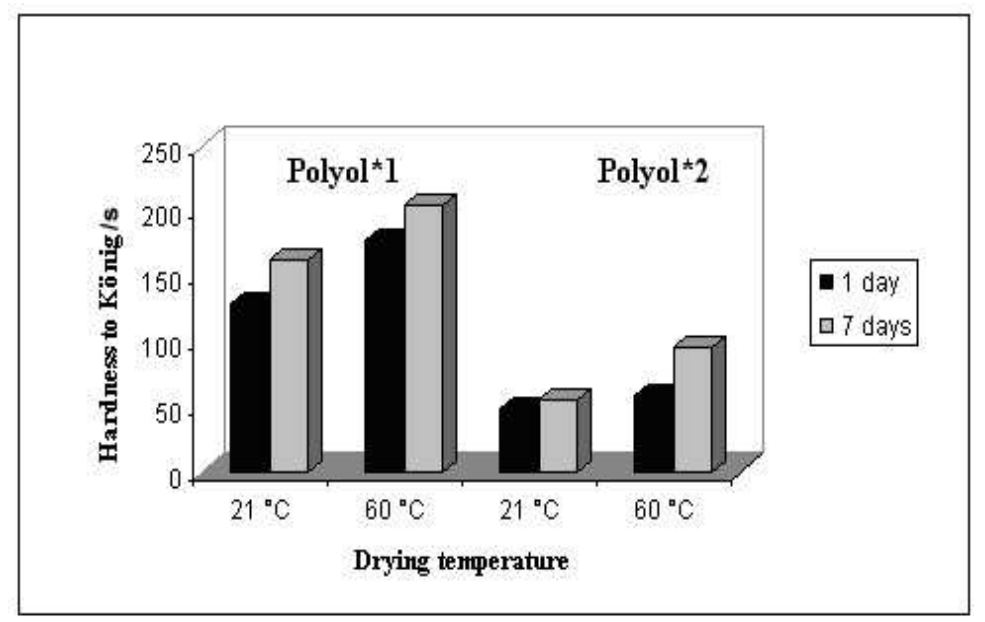

Figure 4. Dependence of the hardness development on drying conditions (applied on a glass plate, $30 \mu \mathrm{m}$ dry film thickness).

Polyol*1 considerably outperforms Polyol*2 in hardness as well as in solvent resistance. It is very significant that the really good crosslinking is reached merely under the forced drying conditions (Figure 4). Only Polyol*1 reaches a good level of crosslinking already at ambient temperature, but in both cases a significant part of the crosslinking agent's capacity is hindered from reacting probably by the chain mobility restrictions.

A rather low crosslinking level of Polyol*2 at ambient temperature comes as a surprise because this kind of polyol performs excellently in $1 \mathrm{C}$ thermosetting applications. Two explanations for this finding are possible, both of which are related to the synthesis route. In the process of the partial esterification of the two acrylic components a certain amount of the carboxyl-functional intermediate remains unreacted in the mixture. This component does not participate in the crosslinking since it is bearing only $\mathrm{COOH}$ groups. It behaves like a plasticizer. Furthermore, the partial esterification of the two 
acrylic intermediates results in small amounts of precrosslinked microgel that could probably be responsible for the early blocking of the crosslinking reaction.

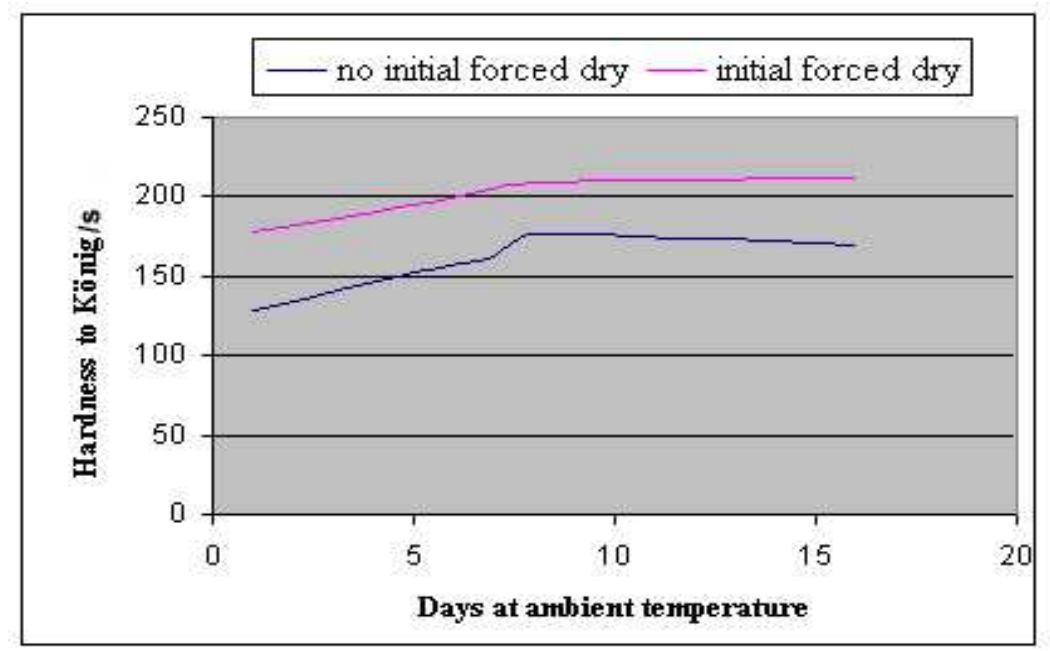

Figure 5. Hardness development of the Polyol*1 based paint depending on the temperature.

At ambient temperature the maximum hardness level is reached after about 8 days (Figure 6). Furthermore, no significant hardness increase can be observed. When initially applying the elevated temperatures $\left(30 \mathrm{~min} 60^{\circ} \mathrm{C}\right.$ ), hardness immediately increases to a much higher level and it is increasing continuously over several days at ambient temperature, which is the behaviour similar to the conventional 2C systems. Similar results have been reported earlier [16].

The use of a more selective manganese catalyst in both PUR 1 and PUR 2 systems has resulted in obtaining a higher level of crosslinking in relation to a less selective zirconium catalyst (Figure 6), as at ambient temperature so too in the process of raising the initial temperature $\left(60^{\circ} \mathrm{C}\right)$. The more selective catalyst promotes the isocyanate-polyol reaction by stimulating a higher level of crosslinking.

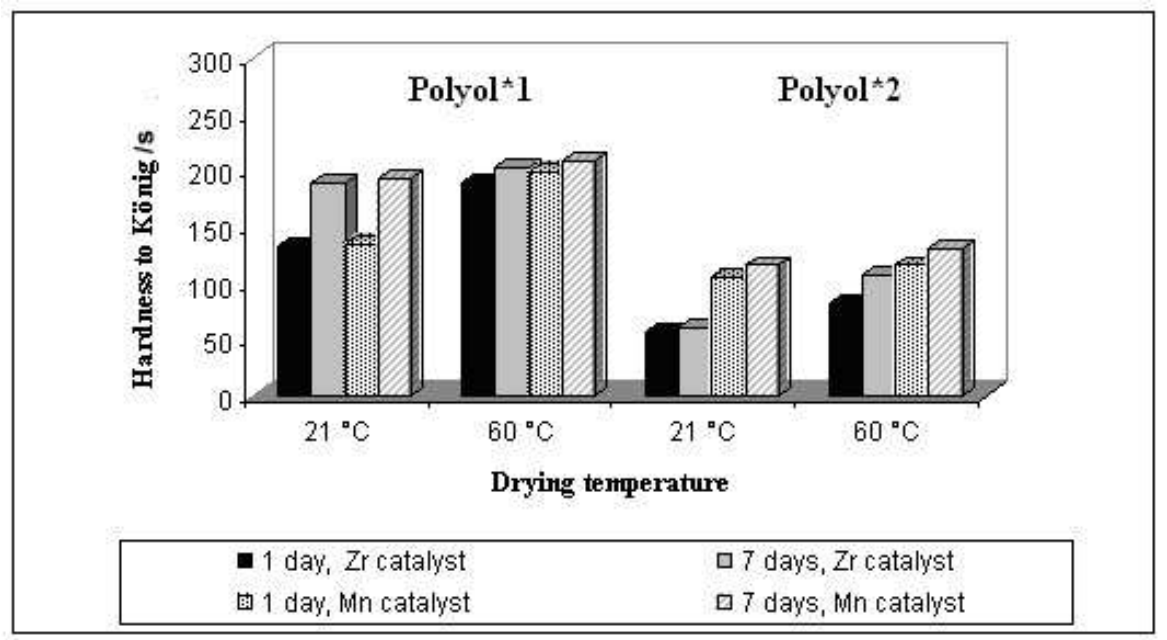

Figure 6. Dependence of the hardness development on the drying conditions, with the applied zirconium catalyst K-KAT ${ }^{\circledR} \mathrm{XC}-6212$ and the manganese based catalyst (applied on a glass plate, 30 $\mu \mathrm{m}$ dry film thickness) 


\subsection{Potlife}

In order to evaluate potlife, the behaviour of the paint has been visually monitored (gassing, viscosity change, coagulation). Unlike the conventional $2 \mathrm{C}$-PU systems that exhibit a steady increase of viscosity, the aqueous 2C-PU paints do not always have a reliable correlation between the viscosity increase and the potlife. Well-stabilized aqueous paints can exist nearly unchanged, in terms of viscosity and appearance, whereas a great part of the reactive groups of the hardener have already been consumed.

Therefore, the paints have been additionally applied onto glass plates immediately after mixing with the hardeners, and in the periods of two and four hours' lag time (induction time) after the paint preparation, respectively. König hardness and gloss of the coating have been measured upon one and seven days' drying at $21^{\circ} \mathrm{C}$.

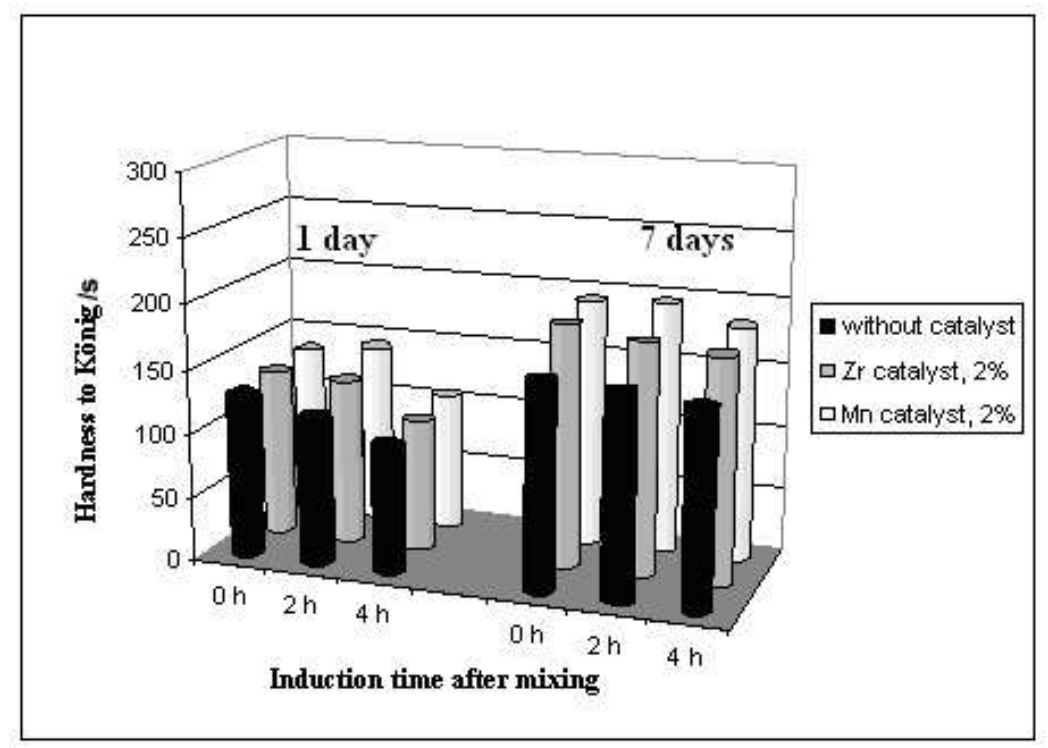

Figure 7. The effect of the potlife on the hardness of the two-component PUR composition coating based on the Polyol*1 (PUR 1), without the catalyst, with the zirconium catalyst K-KAT ${ }^{\circledR}$ XC-6212 and with the manganese based catalyst $(30 \mu \mathrm{m}$ dry film thickness).

The lowering of the hardness that is observed in the system with Polyol*1 during the increasing of the induction time clearly indicates that significant amounts of the isocyanate have already reacted with the polyol and/or water in the pot and are not available for the crosslinking reaction after the film formation. This can be seen from the results obtained at the ambient temperature (Figure 7) as well as at the elevated temperature. The pre-crosslinked areas of the paint are small enough to cause any surface defects because the gloss remains more or less unchanged.

In the systems with the Polyol*1, the use of the zirconium catalyst has made it possible to achieve the König hardness two hours after the induction time, the hardness of 181" upon seven days, while the application of the manganese catalyst has enabled the hardness of 196".

According to the literature data the reaction of water with the polyisocyanate component has the induction period of two hours and so the maximum effect of the activity of the catalyst is achieved just during that induction time [17]. After mixing the components, the same induction time effect on the 
hardness of the formed films has also been obtained in the Polyol 2 , as without the catalyst so too by applying the selective catalysts $\mathrm{Zr}$ and $\mathrm{Mn}$.

The catalytic effect that also affects the gloss of the formed films is shown in Table 3.

Table 3. Measurements of the gloss with the increasing induction time (applied on a glass plate, $30 \mu \mathrm{m}$ dry film thickness; dried for 7 days at $21^{\circ} \mathrm{C} ; 20^{\circ}$ angle).

\begin{tabular}{|c|c|c|c|c|c|c|c|c|c|}
\hline \multirow[t]{2}{*}{ Time } & \multirow{2}{*}{$\begin{array}{l}\text { Polyol*1 } \\
\text { Without } \\
\text { catalyst }\end{array}$} & \multirow{2}{*}{$\begin{array}{l}\text { Polyol*2 } \\
\text { Without } \\
\text { catalyst }\end{array}$} & \multicolumn{2}{|c|}{ Polyol*1 } & \multicolumn{2}{|c|}{ Polyol*2 } & \multicolumn{2}{|c|}{ Polyol*1 } & Polyol*2 \\
\hline & & & $\begin{array}{l}\text { With } \\
\text { catalyst }\end{array}$ & $\mathrm{Zr}$ & $\begin{array}{l}\text { With } \\
\text { catalyst }\end{array}$ & $\mathrm{Zr}$ & $\begin{array}{l}\text { With } \\
\text { catalyst }\end{array}$ & $\mathrm{Mn}$ & $\begin{array}{l}\text { With Mn } \\
\text { catalyst }\end{array}$ \\
\hline $\mathrm{Oh}$ & 75 & 79 & 89.0 & & 94.2 & & 89.8 & & 99.3 \\
\hline $2 \mathrm{~h}$ & 75 & 79 & 89.0 & & 94.2. & & 90.1 & & 99.5 \\
\hline $4 \mathrm{~h}$ & 69 & ---- & 89.0 & & 94.2 & & 89.8 & & 99.3 \\
\hline
\end{tabular}

The above data, combined with the visual observations, have been used to estimate the potlife. The Polyol*1 shows significantly better potlife (4-5 h) than the Polyol*2 (max. 2 h) without the catalyst. The paint systems with the Polyol*2 become increasingly foamy when approaching the end of the potlife, which may indicate a higher degree of side reaction with water. This has not been expected, because this kind of polymer has been shown to be a good emulsifier for other (hydrophobic) acrylics.

By using the selective zirconium and manganese catalysts that catalyze the isocyanate-polyol reaction, the proportion of the isocyanate-hydroxyl reaction has been reduced, so by this the foaming, too, and the potlife in the systems with the Polyol 2 has been extended [6, 7,18-20].

The maximum effect has been achieved two hours after the induction time, indicating that the most compact film having the minimum surface defects has been formed [21].

\section{Conclusions}

The presented results show that the performances of the aqueous two-component polyurethane coatings depend on the polymer structure of the polyols and on the selectivity of the employed catalyst.

The polyol based on the single step synthesis route improves the potlife and hardness.

The addition of the selective catalyst and favouring the isocyanate-polyol reaction contribute to obtaining greater hardness of the formed films.

The examining of the crosslinking level has shown that it is dependent on the temperature at which the crosslinking is taking place as well as on the type of the employed catalyst.

Concerning the catalytic activity, the results of the hardness tests show that the manganese complex obtains the highest catalytic activity two hours after the induction time which points to the optimal time of the catalyst effect.

The catalysts applied in this research enable accomplishing more optimal physical-mechanical properties of the aqueous two-component polyurethane coatings. 


\section{References}

1. Werner, W.J.; Advances in catalysis for organic coatings. Chimia 2002, 56(6), 191-196.

2. Martin, I.K.; Polyurethane dispersions. Polymers Paint Colour Journal 2006, 196, 24-28.

3. David, A. L.; Denise, E. F.; Richard, J. Q.; Optimization of acrylic polyols for low VOC twocomponent water reducible polyurethane coatings using tertiary isocyanate crosslinkers, Progress in Organic Coatings 1999, 35(1-4), 109-116.

4. Johann, B.; Werner, W.; New low VOC Acrylic polyol dispersions for two-component polyurethane coatings", 79 ${ }^{\text {th }}$ Annual Meeting of the FSCT", 5-7 November, Atlanta, 2001.

5. Zeno, W.; Wicks, Jr.; D. A. Wicks; J.; Rosthauser, W.; Two package waterborne urethane systems. Progress in Organic Coatings 2002, 44(2), 161-183.

6. M. Melchiors, M.; Sonntag, C.; Kobusch; Jürgens, E.; Recent developments in aqueous twocomponent polyurethane (2C-PUR) coatings. Progress in Organic Coatings 2000, 40(1-4), 99-109.

7. Blank, W.J.; He, Z.A.; Hessell, E.T.; Catalysis of the isocyanate-hydroxyl reaction by non-tin catalysts. Progr. Org. Coatings 1999, 35, 19-29.

8. He, Z.A.; Blank, W.J.; Picci, M.E.; A selective catalyst for two-component waterborne polyurethane coatings. J. Coatings Tech. 2002, 74, 31-36.

9. K-KAT ${ }^{\circledR}$ XC-6212 a product of King Industries Inc. Norwalk, CT 06852, USA, US pat. 5.846.897.

10. Stamenković, J.; Cakic, S.; Nikolic, G.; Study of the catalytic selectivity of an aqueous twocomponent polyurethane system by FTIR spectroscopy. Chem. Industry 2003, 57, 559-562.

11. Cakic, S.; Lacnjevac, C.; Nikolic, G.; Stamenkovic, J.; Rajkovic, M.; Gligoric, M.; Barac, M.; Spectroscopic characteristics of highly selective manganese catalysts in acqueous polyurethanea systems. Sensors 2006, 6, 1708-1720.

12. Stamenkovic, J.; Cakic, S.; Konstantinovic, S.; Stoilkovic, S.; Catalysis of the isocyanate-hydroxyl reaction by non-tin catalysts in waterborne two-component polyurethane coatings. Facta Universitatis 2004, 2, 243-250.

13. Hovestadt, W.; Klinksiek, B.; Melchiors, M.; Mixing technology of waterborne 2-pack PU coatings. Farbe and Lack. 2000, 106, 40-44.

14. Zhou,X., Tu, W., Hu, J.; Preparation and characterization of two-component waterborne polyurethane comprised of water-soluble acrylic resin and HDI biuret. Chinese Journal of Chemical Engineering 2006, 14(1), 99-104.

15. Christ, U.; High performance - Low VOC-content: Innovative and trend-setting coating systems for industrial applications. Macromolecular Symposia. 2002, 187, 759-770.

16. Macrynal ${ }^{\circledR}$ polyols a product of Solutia Inc. Resins and Additives Business, MO 63141, USA.

17. Bittner, A.; Waterborne two-pack polyurethane coatings for industrial applications, 3rd Nürnberg Congress, March 1955.

18. Hagedus, A.R.; Gilicinski, A. G.; Haney, R. J.; Film formation mechanism of two component waterborne polyurethane coatings. J. Coatings Tech. 1996, 68, 51-61.

19. Hawkins, C.A.; Sheppard, A.C.; Wood, T.G.; Recent advances in aqueous two-component systems for heavy-daty metal protection. Progr. Org. Coatings. 1997, 32, 253-261.

20. Otts, D. B.; Heidenreich E.; Urban, M. W.; Novel waterborne UV-crosslinkable thiol-ene polyurethane dispersions: Synthesis and film formation. Polymer 2005, 46 (19) ,8162-8168. 
21. Cakic, S.; Nikolic, G.; Lacnjevac, C.; Gligoric, M.; Stamenkovic, J.; Rajkovic, M.; Barac, M.; Thermal stability of aqueous polyurethanes depending on the applied catalysts, Sensors 2006, 6, 1697-1707.

(C) 2007 by MDPI (http://www.mdpi.org). Reproduction is permitted for noncommercial purposes. 